\title{
Customary practices, domestic violence, and psychosomatic pain among adolescent mothers in Turkey
}

Yasin Bez, ${ }^{1}$ Cem Uysal, ${ }^{2}$ Mahmut Bulut, ${ }^{3}$ Mehmet Kaya, ${ }^{3}$ Neval Goruk, ${ }^{4}$ Suleyman Demir ${ }^{3}$ and Aytekin Sir $^{3}$

${ }^{1}$ Department of Psychiatry and Behavioral Sciences, University of Miami Miller School of Medicine, Miami, United States of America (Correspondence to: Y. Bez: yasinbez@gmail.com). ${ }^{2}$ Department of Forensic Medicine. ${ }^{3}$ Department of Psychiatry, Dicle University School of Medicine, Diyarbakır, Turkey. ${ }^{4}$ Department of Obstetrics and Gynecology, Memorial Diyarbakır Hospital, Diyarbakır, Turkey.

\begin{abstract}
Background: Adolescent motherhood is present in many societies worldwide, including Turkey.

Aims: We aimed to determine the demographical and cultural characteristics of adolescent mothers, lifetime domestic violence and history of miscarriage, and whether they suffer from any kind of medically unexplained (psychosomatic) pain in a study in south-eastern Turkey.

Methods: We included 501 mothers in this case-control study. The study group comprised 228 mothers who gave their first deliveries at or before 19 years of age, and the control group consisted of 273 mothers who first delivered after 19 years of age. The case-control study was conducted between February and April 2013 in Diyarbakir, Turkey.

Results: Adolescent mothers marry more frequently with their relatives. They have a higher prevalence of culture-bound customary applications such as bride price. They are less likely to be asked for their consent to marry and tend to have more children. They are more frequently victims of domestic violence and more often report medically unexplained psychosomatic pain.

Conclusions: Adolescent motherhood is still a public health problem that seems to be related to certain culture-bound customary practices, continuing domestic violence across generations, increased number of children, and more prevalent psychosomatic pain.
\end{abstract}

Keywords: adolescent motherhood, cultural customs, cultural factors, domestic violence, psychosomatic pain

Citation: Bez Y; Uysal C; Bulut M; Kaya M; Goruk N; Demir S; Sir A. Customary practices, domestic violence, and psychosomatic pain among adolescent mothers in Turkey. East Mediterr Health J. 2018;24(10):994-1001. https://doi.org/10.26719/2018.24.10.994

Received: 03/01/16; accepted: 03/08/17

Copyright (c) World Health Organization (WHO) 2018. Some rights reserved. This work is available under the CC BY-NC-SA 3.o IGO license (https:// creativecommons.org/licenses/by-nc-sa/3.o/igo).

\section{Introduction}

The World Health Organization (WHO) estimates that $10 \%$ of all births worldwide each year are by adolescents aged 15-19 years $(1,2)$. In recent years there has been a growing scientific interest in adolescent pregnancy, which can be defined as pregnancy in girls aged 10-19 years $(1,3)$. Some factors like declining age at menarche, growing independence from parents, premarital sexual relations, and customs that promote marriage in adolescence have led to an increase in adolescent pregnancy in many countries $(1,4)$. Furthermore, it is known that fertility in adolescents rapidly increases with age and reaches up to $13 \%$ by 19 years $(3,5)$.

Since many adolescents are sexually active, voluntary or involuntary pregnancies may occur. Compared to other age groups, adolescent pregnancy and delivery may carry a high risk for mothers and their children, including increased miscarriage, low birth weight, and maternal and infant morbidity and mortality rates (1,2,6-11). Besides health problems, many social problems like lower levels of education, unemployment, financial dependence, domestic violence and child abuse may be seen among women married in adolescence (6,12-15). Moreover, the majority of these factors are known to be associated with psychological problems, including psychosomatic symptoms that are characterized with by unexplained bodily pains (16). Therefore, one may expect higher rates of psychosomatic pain.

In the present study, we aimed to determine the demographic characteristics of adolescent mothers; social, cultural and personal factors that were related to their marriages; history of domestic violence before and after their marriages; age at first pregnancy; number of miscarriages; and whether they suffered from any kind of psychosomatic pain.

\section{Methods}

\section{Study design}

This was a case-control study. Approximately 700 women gave their first birth in a 3-month period in the city of Diyarbakir, Turkey in 2010. The rate of adolescent motherhood was reported to be $32 \%$ among married women in the same geographical area (17). By using the formula at http://www.raosoft.com/samplesize.html, the sample size calculation yielded a sample of 227 study cases with a 5\% error margin and 95\% confidence level. After obtaining the necessary approvals from the Dicle University Ethics Committee the study was conducted between Feb- 
ruary and April 2013 in Diyarbakir. A total of 501 women were enrolled from two sources: (1) women who attended the obstetrics and gynaecology hospital for their pregnancy and had had their first delivery at $\leq 19$ years of age and agreed to participate in the study; and (2) women who were enrolled in an epidemiological study recently conducted by the authors. The case group comprised 228 women who gave their first birth at age $\leq 19$ years (adolescent mothers) and the control group comprised 273 women who delivered their first baby after 19 years of age.

\section{Interview}

All participants were interviewed face-to-face using a semistructured interview form prepared by the authors. To determine the topics to be assessed in this form, Y.B., C.U. and M.C.K. thoroughly searched the available literature using the following keywords "domestic violence", "customary practice, "psychosomatic pain", "bodily pain", "culture", "abuse", "bride price", "berdel", and "miscarriage" in combination with "adolescent motherhood", "adolescent mother", "early age marriage", "adolescent marriage", and "childhood marriage". Available literature published in English and Turkish languages by the end of November 2012 were selected by their relevance. An expert panel, including two adult psychiatrists (Y.B. and M.C.K.), a forensic medicine physician (C.U.), and an obstetrics and gynaecology physician (N.Y.G.), reviewed the selected literature in an 8-hour meeting and created 65 questions in the light of it. Fifty nonleading, nonchallenging and noncriticizing questions (24 open ended, 17 yes or no, and 9 multiple choice) that intended to obtain answers to the study questions were selected by the expert panel in a second meeting. A second group of experts (A.S., M.B., S.D., Y.B., C.U. and M.C.K) critically reviewed the questions in terms of their structure and created the final versions. All questions were simple, clear, free of jargon, easy to ask, and time framed. A standardized form was created and tested on 30 individuals to assess applicability. The question with the lowest response rate was the one that assessed medically unexplained (psychosomatic) pain (83\%). The overall response rate was $91.2 \%$. All questions were asked in the same order to all participants and their answers were recorded immediately on the standardized forms.

The interview form collected information about demographic variables: age at first pregnancy; number of siblings; kinship with the spouse; whether consent to marry was obtained; history of domestic violence before and after marriage (WHO operational definition of domestic violence included acts of physical, sexual and psychological abuse, and control by an intimate partner) (18); whether official and religious weddings were performed; existence of some culture-bound customary practices such as bride price and its amount, berdel (2 men from different families marry each other's sisters without dowry or any bonnet payment), and cradle engagement; history of miscarriage; any type of current domestic violence towards children; whether she was cowife; and existence of medically unexplained bodily pain or psychosomatic pain (pain lasting for $\geq 6$ months that was sufficiently severe to cause significant distress or to interfere with normal activities in the previous year, and that could not be explained by a medical condition or substance use/abuse) (19).

\section{Statistical analysis}

Statistical analysis was performed using SPSS version 18.0 (Chicago, IL, USA). Descriptive variables are presented as frequency and within group percentage, and mean (standard deviation). Categorical variables were compared by $\chi^{2}$ test. Normality of distribution of continuous variables was tested by Kolmogorov-Smirnov test. Continuous variables were compared using Student's $t$ test or its nonparametric equivalent (Mann-Whitney $U$ test). Logistic regression models were tested to understand better the predictors of the current domestic violence of the participants towards their children. All descriptive data, comparisons and the best logistic regression model are presented.

\section{Ethics}

The study was approved by the local Ethics Committee and was conducted in accordance with the ethical standards laid down in the 1964 Declaration of Helsinki and its later amendments.

\section{Results}

There were 501 women with a mean age of 29.9 (13.0) years (range 14-59 years). Mean age of the participants and their spouses at marriage were 18.6 (4.1) and 23.7 (5.0) years. Four hundred and ninety-three (98.4\%) were religiously married while $8(1.6 \%)$ were not. Among those religiously married, 439 (89\%) were legally married, while $54(11 \%)$ were not. Three hundred and seventy-four participants $(74.7 \%)$ reported that they had given consent for their marriage. Two hundred and fifty-one (50.1\%) participants were persuaded to have an arranged marriage; 69 (13.8\%) were forced into an arranged marriage; 111 (22.2\%) were married voluntarily; and $36(6.8 \%)$ were abducted for marriage. Thirty-six participants (7.2\%) did not describe any of these types of marriage. Fifteen (3.0\%) participants were co-wives. Mean age at giving first birth was 19.8 (4.3) years among the whole study participants. Among all participants, 219 (43.7\%) had at least 1 lifetime miscarriage. One hundred and twenty-nine $(25.7 \%)$ participants reported that they had any kind of bodily pain that was considered to be nonorganic in etiology (medically unexplained bodily pain or psychosomatic pain).

Most marriages were based on culture-bound customary practices. Bride price was given for 120 (24\%) participants and cradle engagement or berdel was performed in marriages of $26(5.2 \%)$ participants. One hundred and twenty-three $(24.5 \%)$ participants reported that they were third-degree relatives (first cousins) with their husbands. To understand better the trends in culture-bound customary marriages, similar information was collected for the parents of all participants. Among all participants, 115 women (23\%) reported that their 
parents were third-degree relatives of each other. The percentage of parents who were cousins was also high among women who were married to their cousins (40.6\%, 50 out of 123).

One hundred and thirteen (22.6\%) participants reported domestic violence, either physical or verbal in nature, before their marriages, whereas 79 (15.8\%) reported it only after marriage. Participants with domestic violence before marriage had a significantly higher frequency of domestic violence even after marriage than those who did not report violence before marriage (37.2 and 10.4\%, respectively; $\chi 2=40.18, \mathrm{P}<0.001)$. Three hundred and forty $(67.9 \%)$ participants reported domestic violence neither before nor after marriage; $104(20.7 \%)$ reported it either before or after marriage; and $40(8 \%)$ reported it both before and after marriage. These three groups were asked whether they currently inflicted domestic violence on their children. The latter group reported the highest rate $\left[35.3,48.1\right.$ and $52.5 \%$ in order; $\chi^{2}=8.54$, degrees of freedom $(\mathrm{df})=2, \mathrm{P}=0.014]$. Logistic regression models were tested to show predictors of current domestic violence against children. The best model included the following independent variables: age at marriage and first pregnancy; number of children; kinship with spouse; history of domestic violence before and after marriage; whether she was a co-wife; adolescent pregnancy; and medically unexplained bodily pain (Nagelkerke $\mathrm{R}_{2}=0.13$, $\mathrm{df}=9, \mathrm{P}<0.001$ ) (Table 1). According to this model having a history of domestic violence before marriage, number of children, and medically unexplained bodily pain were significant predictors of domestic violence against children.

Two hundred and twenty-eight (45.5\%) participants who gave their first birth at $\leq 19$ years of age and those who delivered at $>19$ years of age $(n=273,54.5 \%)$ were compared in terms of study variables. Comparisons are shown in Table 2 and Table 3.

\section{Discussion}

Women who became mothers during adolescence face some problems in their later life. According to our results, they marry at an earlier age and more frequently with their relatives; culture-bound customary practices like bride price are more prevalent; they have more children; they are more frequently victims of domestic violence; they may live as a co-wife; and they are less likely to be asked for their consent to marry. It is important to note that they more often report medically unexplained bodily pain that may have undesired personal or familial consequences and increased healthcare utilization.

In our study, the mean age of adolescent mothers at their first delivery was 16.3 (1.3) years, which is earlier than the age reported in previous studies $(3,14)$. One of them reported a mean age of 17.8 (0.7) years and another 18 (1.1) years. The mean age of husbands of adolescent mothers in our study was 22.5 (4.9) years, which is also earlier than the age reported in the previous studies [26.0 (0.3) and 29.2 (4.6) years]. Therefore, our study sample may be considered as a younger population. These differences may be attributed to different geographical and cultural characteristics of the study populations, as the previous studies enrolled participants from a different geographical region of Turkey and Uganda.

In a previous study, most of the women completed both religious and civil marriage rites, while only a few of them were married through either one alone, and only $<1 \%$ were out of religious or civil wedlock (20). In another study conducted in Turkey, $28.1 \%$ of the women who practiced both legal and religious marriage were under age, while underage marriage rose to $44.7 \%$ among those who were only religiously married (21). Consistent with previous studies, civil marriage was less common among adolescent mothers compared to adult mothers in our study, which may be expected since there are also legal limitations for marriage under 18 years of age in Turkey $(22,23)$. Most mothers in our study were asked for their consent to marriage, however the ratio of consenting individuals was lower among adolescent mothers. This might have happened because parents usually do not seek the consent of their adolescent daughters before their marriages, or to the difficulties these adolescents face in making their own decision independently and expressing it to their parents.

In the study by Keskinoglu et al., 945 of 8034 pregnant

\begin{tabular}{|c|c|c|c|c|}
\hline & B & $P$ & $\begin{array}{l}\text { Odds } \\
\text { ratio }\end{array}$ & $\begin{array}{c}95 \% \\
\text { confidence } \\
\text { interval }\end{array}$ \\
\hline Age at marriage & 0.131 & 0.146 & 1.140 & $0.956-1.360$ \\
\hline Age at first pregnancy & -0.112 & 0.238 & 0.894 & $0.742-0.1 .077$ \\
\hline Number of children currently owned & 0.179 & 0.005 & 1.196 & $1.057-1.353$ \\
\hline Existence of kinship with the spouse & 0.070 & 0.794 & 1.073 & $0.653-1.812$ \\
\hline Childhood history of domestic violence & 0.685 & 0.015 & 0.504 & $0.291-0.873$ \\
\hline Domestic violence after marriage & 0.104 & 0.758 & 1.109 & $0.574-2.141$ \\
\hline Being co-wife & 0.803 & 0.278 & 2.231 & $0.524-9.507$ \\
\hline Adolescent pregnancy & 0.590 & 0.149 & 1.804 & $0.810-4.018$ \\
\hline Medically unexplained bodily pain & 0.747 & 0.008 & 0.474 & $0.273-0.823$ \\
\hline
\end{tabular}




\begin{tabular}{|c|c|c|c|c|}
\hline & $\begin{array}{c}\text { Mothers first delivery at } \\
\text { age } \leq 19 \text { years } \\
(\mathrm{n}=228)^{\mathrm{a}} \\
\mathrm{N}(\%)\end{array}$ & $\begin{array}{c}\text { Mothers first delivery at } \\
\text { age }>19 \text { years } \\
(\mathrm{n}=273)^{\mathrm{b}} \\
\mathrm{N}(\%)\end{array}$ & $\chi^{2}$ & $P$ \\
\hline \multicolumn{5}{|c|}{ Parents are relatives } \\
\hline Yes & $90(39.5 \%)$ & $91(33.5 \%)$ & \multirow[b]{2}{*}{1.94} & \multirow[b]{2}{*}{0.163} \\
\hline No & $138(60.5 \%)$ & $181(66.5)$ & & \\
\hline \multicolumn{5}{|c|}{ Domestic violence before marriage } \\
\hline Present & $67(35.1 \%)$ & $46(20.9 \%)$ & \multirow{2}{*}{10.29} & \multirow{2}{*}{0.001} \\
\hline Not present & $124(64.9 \%)$ & $17479.1 \%)$ & & \\
\hline \multicolumn{5}{|c|}{ Religiously married } \\
\hline Yes & $223(97.8 \%)$ & $270(99.6 \%)$ & \multirow[b]{2}{*}{3.46} & \multirow[b]{2}{*}{0.098} \\
\hline No & $5(2.2 \%)$ & $1(0.4 \%)$ & & \\
\hline \multicolumn{5}{|l|}{ Legally married } \\
\hline Yes & $176(77.2 \%)$ & $265(97.4 \%)$ & \multirow{2}{*}{47.78} & \multirow{2}{*}{$<0.00$} \\
\hline No & $52(22.8 \%)$ & $7(2.6 \%)$ & & \\
\hline \multicolumn{5}{|l|}{ Bride price } \\
\hline Yes & $79(35 \%)$ & $41(15.2 \%)$ & \multirow[b]{2}{*}{26.21} & \multirow[b]{2}{*}{$<0.001$} \\
\hline No & $147(65 \%)$ & $229(84.8 \%)$ & & \\
\hline \multicolumn{5}{|c|}{ Consent to marry } \\
\hline Present & $150(67 \%)$ & $224(84.5 \%)$ & \multirow{2}{*}{20.82} & \multirow{2}{*}{$<0.001$} \\
\hline Not present & $74(33 \%)$ & $41(15.5 \%$ & & \\
\hline \multicolumn{5}{|c|}{ Kinship with the spouse } \\
\hline Yes & $105(46.1 \%)$ & $88(32.2 \%)$ & \multirow[b]{2}{*}{10.01} & \multirow{2}{*}{0.002} \\
\hline No & $123(54.9 \%)$ & $185(67.8 \%)$ & & \\
\hline \multicolumn{5}{|c|}{ Existence of any co-wife } \\
\hline Yes & $12(5.7 \%)$ & $3(1.2 \%)$ & \multirow[b]{2}{*}{7.57} & \multirow{2}{*}{0.006} \\
\hline No & $200(94.3 \%)$ & $254(98.8 \%)$ & & \\
\hline \multicolumn{5}{|c|}{ History of miscarriage } \\
\hline Yes & $105(47.7 \%)$ & $114(44.7 \%)$ & \multirow[b]{2}{*}{0.43} & \multirow{2}{*}{0.51} \\
\hline No & $115(52.3 \%)$ & $141(56.3 \%)$ & & \\
\hline \multicolumn{5}{|c|}{ Current domestic violence towards children } \\
\hline Yes & $90(39.8 \%)$ & $101(39.1 \%)$ & \multirow{2}{*}{0.023} & \multirow{2}{*}{0.926} \\
\hline No & $136(60.2 \%)$ & $157(60.9 \%)$ & & \\
\hline Medically unexp & & & & \\
\hline Present & $83(48.3 \%)$ & $46(26.4 \%)$ & & \\
\hline Not present & $89(51.7 \%)$ & $128(73.6 \%)$ & 17.61 & $<0.001$ \\
\hline
\end{tabular}

aSummation of cases for each variable may be different from the total number of cases in this column $(\mathrm{N}=228)$ due to missing data in some cases. Categorical comparisons were made using available data. Percentages were calculated within groups.

${ }^{b}$ Summation of cases for each variable may be different from the total number of cases in this column $(\mathrm{N}=273)$ due to missing data in some cases. Categorical comparisons made using available data. Percentages were calculated within groups.

women who were admitted to their hospital for delivery in 2004 were adolescent mothers aged $\leq 19$ years. Also, the rate of adolescent pregnancy was $\sim 11.8 \%$ and the mean age was 18.1 years (11). In the study conducted by Sir et al., 37\% of the married women reported that they married before 18 years of age and $32 \%$ had their first pregnancy before that age (17). According to our study, the age at first pregnancy was similar to that reported by Sir et al., while the mean age of marriage correlated with the study of Keskinoglu et al.
Adolescent marriages in Middle Eastern countries are largely based on culture-bound practices and traditions. Examples of such marriages include bride exchange (exchange of girls between 2 families), betrothal in the cradle, and bride price paid by groom's family to the bride's family $(5,24)$. In the study by Sir et al., the families of $21 \%$ of the women were reported to receive a bride price to give consent for marriage. In the same study, $7.8 \%$ of the marriages below the age of 18 years and $1.5 \%$ of those over that age were found to be made through betrothal in the 


\begin{tabular}{|c|c|c|c|c|}
\hline & $\begin{array}{c}\text { Mothers first delivery at } \leq \\
19 \text { years of age } \\
(\mathbf{n}=228) \\
\text { Mean } \pm \text { SD }\end{array}$ & $\begin{array}{c}\text { Mothers first } \\
\text { delivery at age }>19 \\
\text { years } \\
(\mathrm{n}=\mathbf{2 7 3}) \\
\text { Mean } \pm \text { SD }\end{array}$ & t or $z$ value & $P$ \\
\hline Number of siblings & $8.4 \pm 2.8$ & $8.13 \pm 2.3$ & 1.3 & 0.16 \\
\hline Age at marriage (years) & $15.6 \pm 1.6$ & $21.1 \pm 3.9$ & -21.1 & $<0.001$ \\
\hline Age of husband at marriage (years) & $22.5 \pm 4.9$ & $24.7 \pm 4.8$ & 4.82 & $<0.001$ \\
\hline Amount of bride price ${ }^{\mathrm{a}}$ & $10.772 \pm 22.69$ & $10.346 \pm 16.21$ & 0.09 & 0.92 \\
\hline Age at first delivery (years) & $16.3 \pm 1.3$ & $22.8 \pm 3.6$ & -26.3 & $<0.001$ \\
\hline Number of children ${ }^{\mathrm{b}}$ & $4(2-5)^{c}$ & $3(2-4)^{c}$ & $4.328^{\mathrm{d}}$ & $<0.001$ \\
\hline
\end{tabular}

${ }^{a}$ Amount is in Turkish Lira.

${ }^{b}$ Mann-Whitney U test performed after Kolmogorov-Smirnov test did not prove normality of distribution.

'Shows median $\left(25^{\text {th }}-75^{\text {th }}\right.$ percentiles).

¿Shows z value.

cradle or bride exchange, and the ratio of these marriages to the total female population was $3.5 \%$ (17), which is in line with our results. Also, our results about bride price demonstrate that adolescent mothers are worth greater amounts and they more frequently become junior wives in a polygamous household.

In some societies, consanguineous marriages are preferred for economic and cultural reasons (25), and they are even observed between uncles and nieces or aunts and nephews (26). In Turkey, consanguineous marriages usually occur between third-degree relatives because of legal and religious restrictions. In a study in Turkey, marriages between blood relatives were mostly observed between paternal cousins (21). In our study, 123 (24.5\%) participants reported that they were third-degree relatives (first cousins) with their husbands. Thus, our study has demonstrated that the rate of consanguineous marriages is more frequent among adolescent mothers.

In the study by Atuyambe et al., $24 \%$ of the adolescent mothers and $13.5 \%$ of the adult mothers were found to have experienced domestic violence from their birth families (14). Another study has pointed out that adolescent mothers are more likely to suffer from domestic violence due to significantly younger age compared to their husbands (21,27-29). Being the junior wife in a polygamous household is also one of the factors associated with facing domestic violence (21). In another study, adolescent mothers were observed to suffer mostly from domestic violence of a physical and sexual nature (30). In our study, adolescent mothers were found to be subject to greater violence both before and after their marriages.

We found that history of domestic violence before marriage, increased number of children owned, and existence of medically unexplained bodily pain were significant predictors of domestic violence towards offspring. Parents who have suffered from domestic violence more frequently show violence to their offspring, which may be considered as inheritance of violence across generations. We observed greater parental violence towards children in families with a larger number of children. A negative correlation between the number of children and the socioeconomic and educational status of the family has been observed previously (29). Families with lower socioeconomic and educational status might resort to violence to set ground rules for their children or might spend less time with their children. Also, families may be overwhelmed with the higher number of children and use violence since they run out of tolerance and patience.

One study found that $14.6 \%$ of the multiparous women started giving birth during adolescence, and $3.9 \%$ of these had $>3$ children (11). Marriage during adolescence means early fertility and greater number of children. The number of miscarriages also increases with the number of births $(17,23,25)$. Our study emphasizes that women who start giving birth during adolescence become more fertile in the long term. In our study, $43.7 \%$ of women had miscarriage at least once in their lives, and it reached $47.7 \%$ among adolescent mothers, which is higher than the rare miscarriage rate in the general population in Turkey ( 21\%).

A quarter of the participants reported any kind of bodily pain that was considered nonorganic in etiology by their physicians. Although determining the type and cause of this kind of pain deserves thorough evaluation by a psychiatrist, it may be an indication of the impaired psychological well-being. The related literature reports higher levels of anxiety disorder and depression in women who became mothers during adolescence (3134). In our study, adolescent mothers were subjected to greater domestic violence, forced marriages, and marriages without the performance of the legal rites. These factors may explain why psychiatric disorders are more common among individuals who become mothers during adolescence. We demonstrated that mothers who complained of psychosomatic pain were more often using violence towards their children. This finding is in accordance with the literature and indicates that psychiatric disorders in one or both parents increase the risk of physical abuse (35).

Despite efforts to improve legal regulations against adolescent marriage, it is still an important worldwide problem, especially in developing countries. Perhaps, 
instead of condemning or trying to forbid this tradition or suggesting punishment for those who engage in adolescent marriage, the right course of action would be to adopt socially appropriate and acceptable approaches to decrease adolescent marriages and consequent pregnancies, while providing support to individuals who have already engaged in it.

This study had some limitations: (1) some of the collected data may have been affected by recall bias as they were based on interviews rather than documentation; (2) the psychological problems and their severity were not assessed using any standardized measurements; and (3) there was inadequate information about the children of the study participants. The strengths of our study included:(1) the study population was in Southeast Turkey (also known as Mesopotamia) where consanguineous and underage marriages below the age of 19 years are prevalent; and (2) the large sample size.

\section{Conclusion}

Our results demonstrate that adolescent marriage and motherhood continue to be serious public health problems. This seems to be related to some culture-bound customary practices, continuing domestic violence across generations, increased number of children, and negative health consequences including medically unexplained bodily pain that potentially can cause increased healthcare utilization.

Funding: None.

Competing interests: None declared

\section{Pratiques coutumières, violence domestique et douleur psychosomatique chez les mères adolescentes en Turquie}

\section{Résumé}

Contexte : Le phénomène de la maternité adolescente existe dans de nombreuses sociétés du monde, y compris en Turquie.

Objectifs : La présente étude, menée dans le sud-est de la Turquie, avait pour objectif d'identifier les caractéristiques démographiques et culturelles des mères adolescentes, d'examiner les antécédents de fausses couches et de violence domestique tout au long de la vie et de déterminer si ces mères ont souffert d'une forme quelconque de douleur (psychosomatique) médicalement inexpliquée.

Méthodes: Nous avons inclus 501 mères dans cette étude cas-témoin. Le groupe d'étude comprenait 228 mères qui avaient eu leur premier accouchement à 19 ans ou avant et le groupe de contrôle comptait 273 mères qui avaient eu leur premier accouchement après 19 ans. L'étude cas-témoin a été réalisée entre février et avril 2013 à Diyarbakir en Turquie.

Résultats : Les mères adolescentes se marient plus souvent avec des membres de leur parenté. Elles présentent une plus forte prévalence d'applications coutumières liées à la culture, comme la pratique du « prix de la fiancée ». Elles sont moins susceptibles de se voir demander leur consentement pour le mariage et ont tendance à avoir davantage d'enfants. Elles sont plus fréquemment victimes de violence domestique et rapportent plus souvent des douleurs psychosomatiques médicalement inexpliquées.

Conclusions: La maternité adolescente représente encore un problème de santé publique. Elle semble associée à certaines pratiques coutumières liées à la culture, à une violence domestique qui se perpétue d'une génération à l'autre, à un nombre élevé d'enfants ainsi qu'à une plus forte prévalence de douleurs psychosomatiques.

$$
\begin{aligned}
& \text { التأثيرات الثقافية، والعنف المنزلي، والآلام النفسية الجسدية بين الأمهات المر اهقات في تركيا }
\end{aligned}
$$

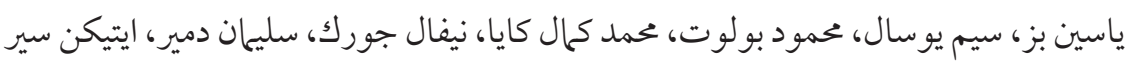

$$
\begin{aligned}
& \text { الخلفية: توجد الأمومة بين المراهقات في العديد من المجتمعات في جميع أنحاء العالم، بها في ذلك تركيا. }
\end{aligned}
$$

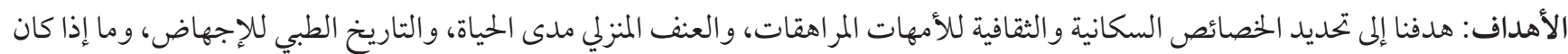

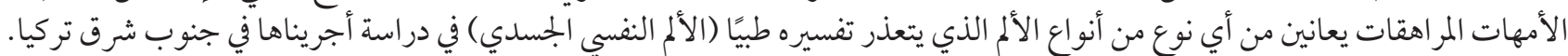

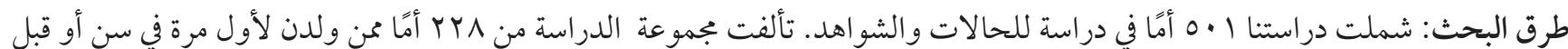

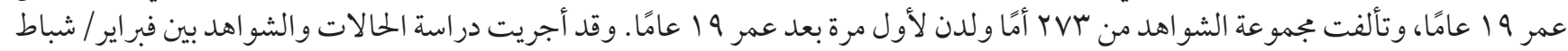

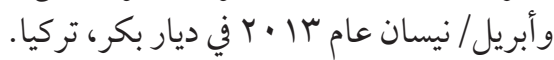

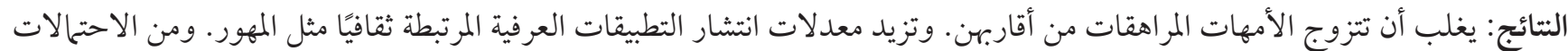

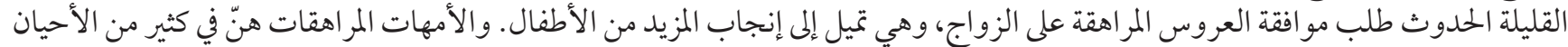

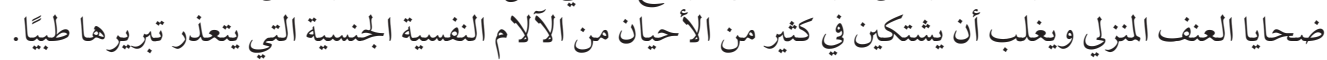




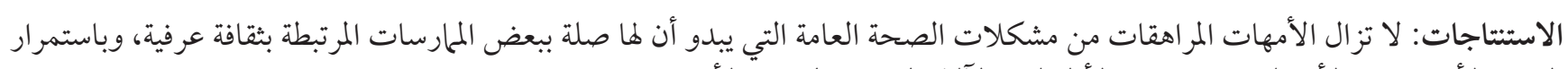

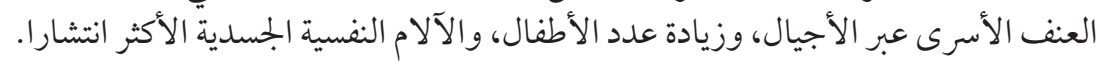

\section{References}

1. Treffers P. World Health Organization Department of Child and Adolescent Health and Development and Department of Reproductive Health and Research. Adolescent pregnancy. Issues in adolescent health and development. Geneva: World Health Organization; 2004 (http://apps.who.int/iris/bitstream/handle/10665/42903/9241591455_eng.pdf?sequence=1, accessed 28 March 2018).

2. McIntyre P. Pregnant adolescents: delivering on global promises of hope. Geneva: World Health Organization; 2006 (http://apps. who.int/iris/bitstream/handle/10665/43368/9241593784_eng.pdf?sequence=1, accessed 28 March 2018).

3. Uzun AK, Orhon FS, Baskan S, Ulukol B. A comparison between adolescent mothers and adult mothers in terms of maternal and infant outcomes at follow-ups. J Matern Fetal Neonatal Med. 2013 Mar;26(5):454-8. https://doi.org/10.3109/14767058.2012.733748 PMID:23020604

4. Atuyambe L, Mirembe F, Johansson A, Kirumira EK, Faxelid E. Experiences of pregnant adolescents - voices from Wakiso district, Uganda. Afr Health Sci. 2005 Dec;5(4):304-9. 10.5555/afhs.2005.5.4.304 PMID:16615840

5. Turkish Demographic Health Survey. [Turkish population and health research]. Ankara: Hacettepe University Institute of Population Studies: 2009. http://www.hips.hacettepe.edu.tr/tnsa2008/data/TNSA-2008_ana_Rapor-tr.pdf, accessed 28 March 2018) (in Turkish)

6. $\quad$ Oner S, Yapici G. Glance at adolescent pregnancies. Turk J Public Health. 2010;8(1):30-9.

7. Chen XK, Wen SW, Fleming N, Demissie K, Rhoads GG, Walker M. Teenage pregnancy and adverse birth outcomes: a large population based retrospective cohort study. Int J Epidemiol. 2007 Apr;36(2):368-73. https://doi.org/10.1093/ije/dyl284 PMID:17213208

8. Klein JD; American Academy of Pediatrics Committee on Adolescence. Adolescent pregnancy: current trends and issues. Pediatrics. 2005 Jul;116(1):281-6. https://doi.org/10.1542/peds.2005-0999 PMID:15995071

9. Al-Sahab B, Heifetz M, Tamim H, Bohr Y, Connolly J. Prevalence and characteristics of teen motherhood in Canada. Matern Child Health J. 2012 Jan;16(1):228-34. https://doi.org/10.1007/s10995-011-0750-8 PMID:21298506

10. Kongnyuy EJ, Nana PN, Fomulu N, Wiysonge SC, Kouam L, Doh AS. Adverse perinatal outcomes of adolescent pregnancies in Cameroon. Matern Child Health J. 2008 Mar;12(2):149-54. https://doi.org/10.1007/s10995-007-0235-y PMID:17562148

11. Keskinoglu P, Bilgic N, Picakciefe M, Giray H, Karakus N, Gunay T. Perinatal outcomes and risk factors of Turkish adolescent mothers. J Pediatr Adolesc Gynecol. 2007 Feb;20(1):19-24. https://doi.org/10.1016/j.jpag.2006.10.012 PMID:17289512

12. Rodríguez MA, Jiménez MA. Epidemiological assessment of the influence of socio-family factors in adolescent pregnancy. Eur J Epidemiol. 2001;17(7):653-9. https://doi.org/10.1023/A:1015555314059 PMID:12086079

13. Singh S, Darroch JE, Frost JJ. Socioeconomic disadvantage and adolescent women's sexual and reproductive behavior: the case of five developed countries. Fam Plann Perspect. 2001 Nov-Dec;33(6):251-8, 289. https://doi.org/10.2307/3030192 PMID:11804434

14. Atuyambe L, Mirembe F, Tumwesigye NM, Annika J, Kirumira EK, Faxelid E. Adolescent and adult first time mothers' health seeking practices during pregnancy and early motherhood in Wakiso district, central Uganda. Reprod Health. 2008 12 30;5(1):13. https://doi.org/10.1186/1742-4755-5-13 PMID:19116011

15. Puri M, Frost M, Tamang J, Lamichhane P, Shah I. The prevalence and determinants of sexual violence against young married women by husbands in rural Nepal. BMC Res Notes. 2012 Jun 13;5(1):291. https://doi.org/10.1186/1756-0500-5-291 PMID:22695085

16. Davis AA. Younger and older African American adolescent mothers' relationships with their mothers and female peers. J Adolesc Res. 2002;17(5):491-508. https://doi.org/10.1177/0743558402175004

17. Sir A, Kaya I, Kaya MC, Bez Y. Early age marriages: Diyarbakir sample. In: Senol D, Yildiz S, Kiymaz T, Kala H, editors. The symposium of violence against women and children). Ankara: Neyir Matbaacllı; 2012.

18. Kalokhe AS, Potdar RR, Stephenson R, Dunkle KL, Paranjape A, Del Rio C, et al. How well does the World Health Organization definition of domestic violence work for India? PLoS One. 2015 Mar 26;10(3):e0120909. https://doi.org/10.1371/journal. pone.0120909 PMID:25811374

19. Park S, Cho MJ, Seong S, Shin SY, Sohn J, Hahm BJ, et al. Psychiatric morbidities, sleep disturbances, suicidality, and quality-of-life in a community population with medically unexplained pain in Korea. Psychiatry Res. 2012 Aug 15;198(3):509-15. https://doi. org/10.1016/j.psychres.2012.01.028 PMID:22424895

20. Turan N, Dokgoz H. Child mothers. Bull Forensic Med. 2007;12(3):136-41.

21. Yuksel-Kaptanoglu I, Ergocmen B. Factors that pave the way for becoming a child bride. J Sociol Res. 2012;15(2):128-61.

22. Coban AI. Adolescent marriages. Fam Soc. 2009;4(16):37-50.

23. Duvan CI, Turhan NO, Onaran Y, Gumus YH, Gozdemir E. Adolescent pregnancies: maternal and fetal outcomes. N J Med. 2010;27:113-6.

24. Altinay AG, Arat Y. Violence against women in Turkey: a nationwide survey. Istanbul: Punto Publishing Solutions; 2009. http:// research.sabanciuniv.edu/11418/1/Violence_Against_Women_in_Turkey.pdf 
25. Hamamy H. Consanguineous marriages: preconception consultation in primary health care settings. J Community Genet. 2012 Jul;3(3):185-92. https://doi.org/10.1007/s12687-011-0072-y PMID:22109912

26. Hafez M, El-Tahan H, Awadalla M, El-Khayat H, Abdel-Gafar A, Ghoneim M. Consanguineous matings in the Egyptian population. J Med Genet. 1983 Feb;20(1):58-60. https://doi.org/10.1136/jmg.20.1.58 PMID:6842535

27. Arslantas H, Adana F, Ergin F, Gey N, Biçer N, Kiransal N. Domestic violence during pregnancy in an eastern city of Turkey: a field study. J Interpers Violence. 2012 May;27(7):1293-313. https://doi.org/10.1177/0886260511425248 PMID:22080579

28. Clark CJ, Silverman JG, Shahrouri M, Everson-Rose S, Groce N. The role of the extended family in women's risk of intimate partner violence in Jordan. Soc Sci Med. 2010 Jan;70(1):144-51. https://doi.org/10.1016/j.socscimed.2009.09.024 PMID:19837499

29. Edirne T, Can M, Kolusari A, Yildizhan R, Adali E, Akdag B. Trends, characteristics, and outcomes of adolescent pregnancy in eastern Turkey. Int J Gynaecol Obstet. 2010 Aug;110(2):105-8. https://doi.org/10.1016/j.ijgo.2010.03.012 PMID:20434724

30. Jewkes R. Intimate partner violence: causes and prevention. Lancet. 2002 Apr 20;359(9315):1423-9. https://doi.org/10.1016/So1406736(02)08357-5 PMID:11978358

31. Birkeland R, Thompson JK, Phares V. Adolescent motherhood and postpartum depression. J Clin Child Adolesc Psychol. 2005 Jun;34(2):292-300. https://doi.org/10.1207/s15374424jccp3402_8 PMID:15901229

32. Eshbaugh EM, Lempers J, Luze GJ. Objective and self-perceived resources as predictors of depression among urban and non-urban adolescent mothers. J Youth Adolesc. 2006;35(5):833-47. https://doi.org/10.1007/s10964-006-9108-8

33. Steinberg JR, Russo NF. Abortion and anxiety: what's the relationship? Soc Sci Med. 2008 Jul;67(2):238-52. https://doi. org/10.1016/j.socscimed.2008.03.033 PMID:18468755

34. McGuinness TM, Medrano B, Hodges A. Update on adolescent motherhood and postpartum depression. J Psychosoc Nurs Ment Health Serv. 2013 Feb;51(2):15-8. https://doi.org/10.3928/02793695-20130109-02 PMID:23330798

35. Arman A. Child psychiatry perspectives on child abuse and neglect. In: Polat O, editor. All aspects of child abuse. Volume 2. Ankara: Seçkin Publishing; 2007. pp. 139-50. 